\title{
Biomedical Significance of Tryptamine: A Review
}

Shazia Kousara*, Sadia Noreen Anjuma, Farrukh Jaleela, Jallat Khana and Sidra Naseema

Department of Chemistry, Khwaja Fareed University of Engineering and Information Technology, Rahim Yar khan, Pakistan

*Corresponding Author: Shazia Kousara, Department of Chemistry, Khwaja Fareed University of Engineering and Information Technology, Rahim Yar khan, Pakistan, Tel: (92) 3027086227; Fax: (068) 9239122; E-mail: Shazia_hej@hotmail.com

Received date: Sep 07, 2017; Accepted date: Sep 25, 2017; Published date: Oct 02, 2017

Copyright: @ 2017 Kousara S, et al. This is an open-access article distributed under the terms of the Creative Commons Attribution License, which permits unrestricted use, distribution and reproduction in any medium, provided the original author and source are credited.

\begin{abstract}
Tryptamine the important psychotropic drug having indole ring has wider biological and pharmaceutical significance. The focus is to see the relevant and recent achievements as neurotransmitter and neuromodulator, vasoconstrictor and vasodilator, antimicrobial and antibacterial, antioxidant and antifungal agents. Tryptamine and its natural and synthetic derivative have been reported for the variety of biological significance in the above mentioned area. This review covers all these aspects in a comprehensive way.
\end{abstract}

Keywords: Tryptamine; Neurotransmitter; Neuromodulator; Psychotropic drug

\section{Introduction}

Tryptamine, a monoamine alkaloid containing an indole ring structure is derived by the decarboxylation of amino acid tryptophan [1]. The indole ring is the important nucleus of many complex natural products having importance in drug discovery and a variety of naturally occurring, synthetic and semi-synthetic drugs are based on tryptamine skeleton. Tryptamine is found in fungi, plants and animals [2]. Tryptamine structural distinction is in approximation to the neurotransmitter serotonin and as hallucinogens and well-known drugs in these classes are DMT etc. Its importance as the neurotransmitter, neuromodulator and as psychedelic drugs is well known because of its presence in mammalian brain in trace amount approximately $3.5 \mathrm{~mol} / \mathrm{g}[3,4]$.

Tryptamine analogues produced by its synthetic modification play a vital role in human life due to the introduction of biologically active functionalities in its nucleus which may cause alterations of the physical and mental status of human brain. A variety of neuroactive compounds ranging from toxic substances to anti-migraine drugs, such as sumatriptan, rizatriptan and zolmitriptan are produced by substitutions on the indole ring at C-2 and nitrogen of its side chain [5]. For producing psychotropic phenomena, a trace amount of tryptamine is required due to its intoxications and fatalities for several reasons.

\section{Biomedical Significance of Tryptamine}

\section{Plants containing tryptamine}

In plants tryptamine in trace amount acts as a promising stage to the plant hormone indole-3-acetic acid in one biosynthetic pathway. Many Acacia species contains the list of psychoactive alkaloids and among one of these is tryptamine present in elevated level. Tryptamine derivative DMT (N, N-dimethyltryptamine) (I) is the active constituent for the hallucinogenic effect of brew known as the "vine of the souls" i.e Ayahuasca [6, 7].
Traditionally this drink is used in indigenous amazonian tribes in religious ceremonies as well for therapeutic purposes in northern South America for the effective treatment of abuse disorders and some physical maladies [8]. Ayahuasca, the most common tea with the considerable amount of DMT have ethnomedicine applications and many other plants are also the source of DMT [9]. The most common hallucinogenic fungi contains derivatives of tryptamine are the "magic mushrooms" which belongs to Psilocybecubens species comprising psilocybin (4-phosphoryloxy-N, N-dimethyltryptamine) (XI) and psilocin (4-hydroxy-N, N-dimethyltryptamine) (X) have well-known psychotropic effects [6]. Psilocybin and psilocin have (lysergic acid diethylamide) LSD-like properties and produce changes in perception and behavior [10].

\section{Tryptamine Derivatives and Their Biomedical Significance}

\section{Natural derivative}

There is the good number of naturally occurring tryptamines occurring in plants, animals. Serotonin the important neurotransmitter increases serotonergic activity of human brain and melatonin a hormone concerned to maintain the sleep-wake cycles are important natural derivative of tryptamine. Serotonin (5hydroxytryptamine, 5-HT) (II), the important signaling hormones involved in central nervous system regulation and harmonization of many processes such as temperature regulation, memory, sleep, cognition and behavior etc. [11]. Melatonin (N-acetyl-5methoxytrypatmine) (III), rhythm and regulates diverse physiological processes through the secretion of pineal gland and this pinealproduced melatonin acts mostly as an endocrine substance. A number of functions of extrapineal-derived melatonin as endocrine, autocrine or paracrine substance as well as regulation of many G1 function such as proliferation of epithelium, water and ion transport, acid secretion, motility and immune system [12].

\section{Synthetic derivative}

The design and synthesis of highly selective sumatriptan (IV), [13] drug has resulted through the study and classification of 5- 
Page 2 of 6

hydroxytryptamine receptors for migraine treatment. Similarly ondansetron (VII) [14] and alosetron (VIII) [15] synthesized through these studies for nausea and vomiting suppression caused by cancer chemotherapy and radiotherapy and for irritable bowel syndrome treatment respectively [16].

The tryptamine derivative a-methyltryptamine (V) has multidimensional functions (Table 1) such as antidepressant, powerful psychedelic drug, stimulant and monoamine oxidase inhibitor etc. Similarly, it's N, N-Dimethyltryptamine (I) analogue preparation by ancient and modern South American cultures as a hallucinogenic indole alkaloid that occurs naturally in a variety of plants [17]. Securinine (TPS) derived tryptamine (IX) derivative belongs to Euphorbiaceae family has found antioxidant along with mito and cytoprotective activities [18].

\section{Halogen derivatives}

In the field of radiopharmaceuticals production for nuclear medicine and positron emission topography (PET), the introduction of $18 \mathrm{~F}, 79 \mathrm{Br}, 81 \mathrm{Br}$ and $131 \mathrm{I}$ by replacement of hydrogen had played a vital role in enhancing the biological significance of tryptamine [19].

Through investigation of halogen metabolism, the potential radiopharmaceutical 18F-tryptamine is the subject of essential research in nuclear medicine because of its promising effect in Parkinson, Alzheimer and Schizophrenia diseases for abnormal brain stress monitoring [20].

\section{Tryptamine as neurotransmitter}

The studies shows that enzymatic decarboxylation of amino acids leads to alkaloids such as L-ADDC enzyme found in serum of various animals and humans is an effective catalyst for tryptamine production as well as pyridoxal phosphate (PLP) distributed in mammalian tissues responsible for the production of serotinine and melatonin [21]. The regional distribution in both striatum and hypothalamus of 5hydroxytryptamine a well-known neurotransmitter helps in regulation of alcoholism in humans as well as mood, sleep and anxiety in mammals [22]. The renowned 5-HT biogenic amine as neurotransmitter to regulate human CNS such as mood-anxiety, aggressiveness, impulsivity, cognition, feeding behaviours and body temperature also contribute in modulation of peripheral activities such as in the gut function, the immune and inflammatory responses, blood stem cells differentiation and hemodynamic functions [23].

The alteration of 5-HT transmission has resulted in autism and cognitive deficit, mood-affective disorders [24], obesity and other syndromes with peripheral symptoms such as chronic fatigue syndrome and irritable bowel syndrome (IBS) etc. [25]. The scavenging properties of circadian regulators, N-acetyl-5-HT (NAS) and melatonin (MLT) is due to indoleamines in 5-HT moiety and through "kynurenine shunt" a number of molecules produce in vertebrates and humans, are involved in inflammation, excitatory neurotransmission, immune response and many other functions [26].

\section{Tryptamine as neuromodulator}

Neuromodulator function to attenuate or amplify information at synaptic junctions transferred by neurotransmitter and central effects of $5 \mathrm{HT}$ can be modified by tryptamine in both positive and negative direction. Similarly in mammalian CNS, tryptamine and its derivatives such as dimethyltryptamine so-called "trace amines" act as neuromodulator [27]. Neuropsychiatric manifestations arises due to the disturbance in synthesis and metabolism of tryptamine and urinary output of tryptamine is correlated with increasing severity of psychosis as Schizophrenic, Parkinsonion and depressed patients has disturbed urinary output of tryptamine [28].

\section{Tryptamine as vasoconstrictor}

Tryptamine, a trace indirect sympathomimetic amine and subtype of vascular 5-HT like receptors are not consistently dispersed over cardiovascular system [29]. By vasoconstriction, tryptamine enhances blood pressure because of noradrenaline discharge from sympathetic neurons [30]. Tryptamine correlate with 5-HT receptors due to its structural resemblance [30], produced vasoconstrictor responses in mmole range as in rabbit, narrowing of aorta occur due to undeviating in cooperation of 5-HT receptors and $\alpha$-adrenoceptors [31]. Sumatriptan, unique receptor agonist similar to 5-HT also generate vasoconstrictor responses, however these responses are limited to definite blood vessels in vitro and restricted to the cerebral vascular beds in vivo [32]. As compared to the blood and urine the concentration of tryptamine is higher in human brain and its level goes up after tryptamine rich food is taken in diet [33]. Vasocostrictor responses induced by tryptamine can be terminating by 5 -HT2A receptor antagonists, ritanserin and ketanserin [34].

\section{Tryptamine as vasodilator}

A tryptamine analogue 5-CT (5-Carboxamidotryptamine) (VI) has a powerful vasodilator effect in vivo and vitro studies due to its undeviating act on vascular smooth muscle [35]. However in specific vascular beds, 5-CT has been revealed to generate vasoconstrictor responses [36]. In diverse vascular regions of a variety of species, such as dogs [37] rabbit, pig, [38] monkey [39] and neonatal porcine vena cava [40]. 5-HT7 receptors have been revealed to intercede vasodilatation [41]. Increase of perfusion pressure through phenylephrine infusion results in a marked vasodilator response when tryptamine was tested in the presence of ritanserin in mesenteric vascular beds [42]. The trace amines i.e tyramine and $\beta$-PEA ( $\beta$ phenylethylamine) show vasodilator response under perfusion pressure similar to tryptamine due to the activation of TAARs (trace amine-associated receptors) and this affect is eliminated by the action of L-NAME (NG-nitro-L-arginine methyl ester) [30].

\section{Discussion}

\section{Antimicrobial, anti-oxidant and antibacterial activity of tryptamine}

Hetrocyclic compound have a lot of importance in the field of pharmaceuticals and industries. Tryptamine derivatives show [43-48] significant properties such as anti-oxidant, anti-inflammatory [47], antibacterial activity [48]. Tryptamines have an indole ring structure and antimicrobial activity is due to presence of pyrrolidine ring [44]. According to Chinese academy of science shanghai, anti-viral activity against hepatitis B virus shown by series of tryptamine derivatives. Many tryptamine derivatives show antimicrobial and antibacterial activities especially tryptamine based sulfonamide-compounds (XII) widely used as antibacterial and antimicrobial agents [45].

Moreover, doubly phenylated tryptamine also shows anti-microbial activity [46]. Reactive oxygen species (ROS) production can also cause a range of chronic health troubles such as cancer, ageing, Parkinson's 
Citation: Kousara S, Anjuma SN, Jaleela F, Khana J, Naseema S (2017) Biomedical Significance of Tryptamine: A Review. J Pharmacovigil 5:

Page 3 of 6

disease and Alzheimer's disease [49]. Production of ROS is regularized by natural anti-oxidants. Synthesis of a series of novel phosphorylated derivatives of tryptamine (XIII) by Staudinger reaction show antioxidant properties because of presence of nitro, chlorine and aldehyde as functional groups in hetero cyclic rings, these compound acts as good antioxidants [50].

Epilepsy is one of the most common diseases of the nervous system. In the pathogenesis of epilepsy oxidative stress plays a significant role [51]. A new tryptamine derivative of securinine (TPS) (IX) has antioxidant as well as cytoprotective activities [52]. TPS is a secondary metabolite of a plant from the Euphorbiaceae family, which act as antioxidant.

\section{Antifungal activity}

Tryptamine derivative exhibited potential antibacterial and antifungal activities by using fungal strain of Aspergillus Niger Such as $\mathrm{N}$-(2-(1H-Indol-3-yl)ethyl)-4-fluorobenzenesulfonamide (XIV), N-(2(1H-Indol-3-yl)ethyl)-4-nitrobenzenesulfonamide (XV) and $\mathrm{N}-(2-$ (1H-Indol-3-yl)ethyl)-4-chloro-3-nitrobenzenesulfonamide (XVI) showed prevention of growth of tested microorganisms exhibited potent antimicrobial activity (Table 1). These sulfonamide derivatives have been widely used for bacterial, protozoal and fungal infections and in safe therapeutic dosage ranges are among first effective chemotherapeutic agent [53].

\begin{tabular}{|c|c|c|}
\hline Name of compound & Structure & Biomedical significance \\
\hline DMT (N, N-dimethyltryptamine) (I) & & $\begin{array}{l}\text { A powerful psychedelic compound Known as "vine of } \\
\text { the souls". }\end{array}$ \\
\hline Serotonin (5-hydroxytryptamine, 5-HT) (II) & & neurotransmitter and signalling hormones in CNS \\
\hline Melatonin (N-acetyl-5-methoxytrypatmine) (III) & & $\begin{array}{l}\text { Control of diurnal rhythm of various physiological } \\
\text { functions }\end{array}$ \\
\hline Sumatriptan (IV) & & For migraine treatment \\
\hline a-methyltryptamine $(\mathrm{V})$ & & $\begin{array}{l}\text { Antidepressant, stimulant, psychedelic drug, } \\
\text { monoamine oxidase inhibitor etc. }\end{array}$ \\
\hline 5-CT (5-Carboxamidotryptamine) (VI) & & Vasodilator and vasoconstictor effect. \\
\hline Ondansetron (VII) & & $\begin{array}{l}\text { Nausea and vomiting suppression caused by cancer } \\
\text { chemotherapy and radiotherapy }\end{array}$ \\
\hline
\end{tabular}


Citation: Kousara S, Anjuma SN, Jaleela F, Khana J, Naseema S (2017) Biomedical Significance of Tryptamine: A Review. J Pharmacovigil 5: 239. doi:10.4172/2329-6887.1000239

Page 4 of 6

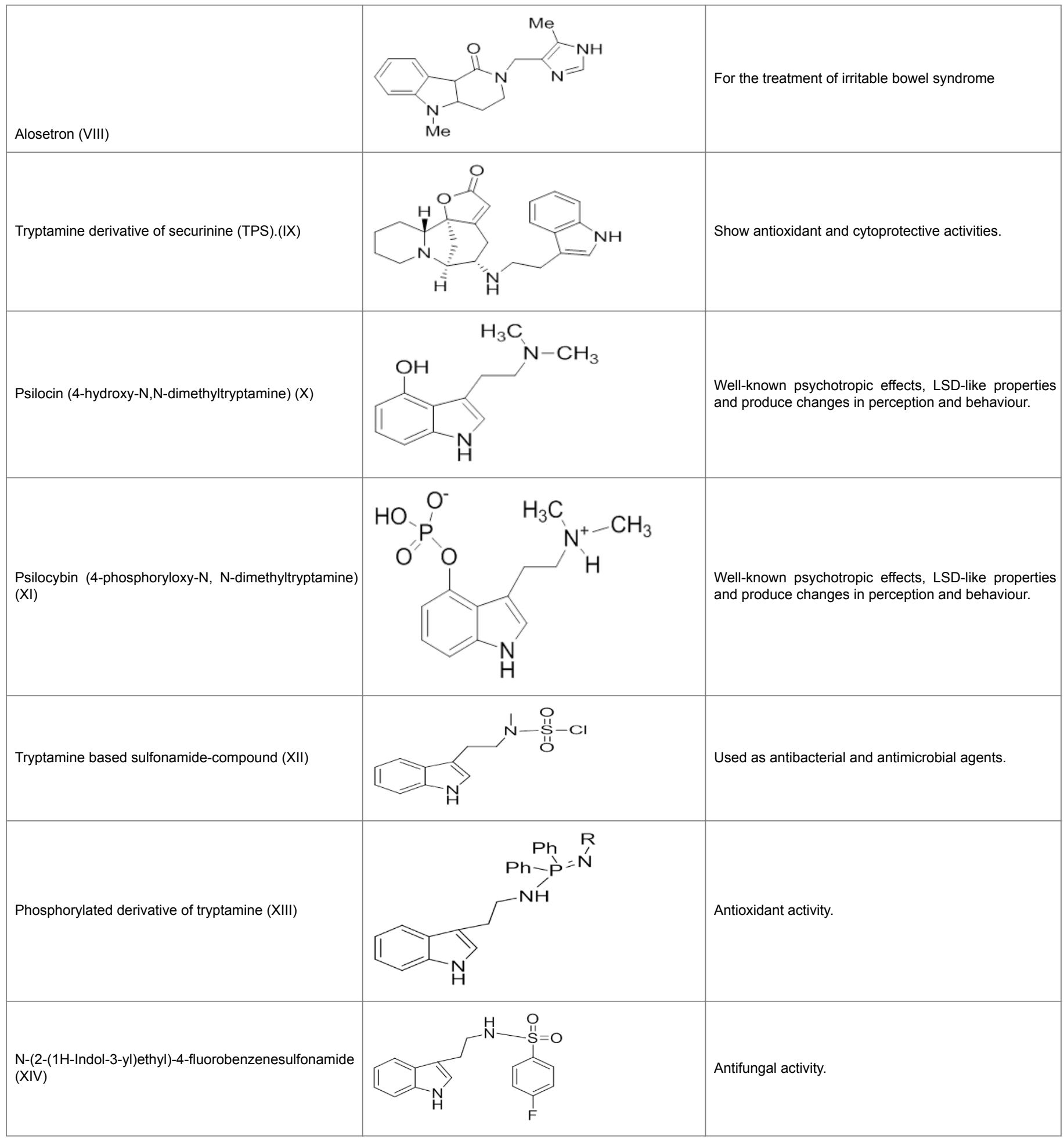




\begin{tabular}{|l|l|l|l|}
\hline \\
(XV) \\
fluorobenzenesulfonamide \\
fl-(1H-Indol-3-yl)ethyl)-4-nitrobenzenesulfonamide
\end{tabular}

Table 1: Biomedical significance of tryptamine derivatives.

\section{Toxicity of tryptamine}

Tryptamines and phenelthylamines are used for psychological and medicinal purpose (licit use) and illicit use for frivolous purposes (illicit use). Although tryptamine plays several important functions but it has toxic effect also. According to Nichols, because of lack of affinity for the relevant receptors and targets, the tryptamine group are usually doubtful to "cause death-dealing changes in cardio-vascular, renal or hepatic function", but the use of a-methyl tryptamine/a-methoxy tryptamine (AMT) or 5-MeO-AMT('foxy') lead with US fatalities. However the potency of tryptamine enhanced when methoxyl group is attached in tryptamine ring at position 5. Disturbance in behaviour may also lead due to hallucinogenic effects of tryptamines, so patient face life-threatening situations. Severe cardiac failure may also occur due to over dose of this drug.

\section{Conclusion}

Trypytamine a mono amine alkaloid is present in fungi, plants and animals is important heterocyclic compound in drug discovery studies. Among potential naturally occurring products this is considered important type of molecule which is also present in mammalian brain in trace amount. Tryptamine plays important biomedical role as neurotransmitter and neuromodulator, vasoconstrictor and vasodilator, antimicrobial and antibacterial, antioxidant and antifungal agents. Its modification at different position leads to many compounds of pharmacological importance. Large numbers of research are currently in progress on tryptamine and its derivatives. This paper reviews the current status and the recent studies of biologically active tryptamine and its derivatives and this will promote various research activities in growing this field.

\section{References}

1. Murch SJ, Campbell SSB, Saxena PK (2001) The role of serotonin and melatonin in plant morphogenesis: Regulation of auxin induced root organogenesis in in vitro-cultured explants of St. John's wort (Hypericum perforatum L.). In Vitro Cellular \& Developmental Biology - Plant 37: 786-793.

2. Corkery JM, Durkin E, Elliott S, Schifano F, Ghodse AH (2012) The recreational tryptamine 5-MeO-DALT (N, N-diallyl-5methoxytryptamine): A brief review. Prog Neuropsychopharmacol Biol Psychiatry 39: 259-262.
3. Jones RS (1982) Tryptamine: A neuromodulator or neurotransmitter in mammalian brain? Prog Neurobiol 19: 117-139.

4. Mahmood ZA, Ahmed SW, Azhar I, Sualeh M, Baig MT, et al. (2010) Bioactive alkaloids produced by fungi. I. Updates on alkaloids from the species of the genra boletus, fusarium and psilocybe. Pak J Pharm Sci 23: 349-357.

5. Hill SL, Thomas SH (2011) Clinical Toxicology of newer recreational drugs. Clin Toxicol (Phila) 49: 705-719.

6. Tittarelli R, Mannocchi G, Pantano F, Romolo FS (2015) Recreational use, analysis and toxicity of Tryptamines. Current Neuropharmacol 13: 26-46.

7. Santos RG, Landeira-Fernandez J, Strassman RJ, Motta V, Cruz AP (2007) Effects of ayahuasca on psychometric measures of anxiety, panic-like and hopelessness in Santo Daime members. J Ethnopharmacol 112: 507-513.

8. Ujvary I (2014) Psychoactive natural products: Overview of recent developments. Ann Ist Super Sanita 50: 12-27.

9. Araujo AM, Carvalho F, Bastos Mde L, Guedes de Pinho P, Carvalho M (2015) The hallucinogenic world of tryptamines: An updated review. Arch Toxicol 89: 1151-1173.

10. Cunningham N (2008) Hallucinogenic plants of abuse. Emerg Med Australas 20: 167-174.

11. Araujo AM, Carvalho F, Bastos Mde L, Guedes de Pinho P, Carvalho M (2015) The role of the serotonin receptor subtypes 5-HT1A and 5-HT7 and its interaction in emotional learning and memory. Front Pharmacol 6: 162 .

12. Ahmed R, Mahavadi S, Al-Shboul O, Bhattacharya S, Grider JR, et al. (2013) Characterization of signaling pathways coupled to melatonin receptors in gastrointestinal smooth muscle. Regul Pept 184: 96-103.

13. Freidank-Mueschenborn E, Fox AW (2005) Resolution of concentration response differences in onset of effect between subcutaneous and oral sumatriptan. Headache 45: 632-637.

14. Generali JA, Cada DJ (2009) Off-label drug uses-Ondansetron: Postanesthetic shivering. Hospital Pharmacy 44: 670-671.

15. Horton R (2001) Lotronex and the FDA: A fatal erosion of integrity. Lancet 357: 1544-1545.

16. Kaushik NK, Kaushik N, Attri P, Kumar N, Kim CH, et al. (2013) Biomedical Importance of Indoles. Molecules 18: 6620-6662.

17. Narasaiah T, Subba DR, Ramana KV, Adam S, Raju CN (2012) Synthesis of new sulfonamide derivatives of tryptamine and their antimicrobial activity. Der Pharma Chemica 4: 1582-1590.

18. Neganovar ME, Blik VA, Klochkov SG, Chepurnova NE, Shevtsova EF (2011) Investigation of the antioxidant characteristics of a new tryptamine derivative of securinine and its influence on seizure activity in the brain in experimental epilepsy. Neurochemical Journal 5: 208. 
19. Bomanji JB, Costa DC, Ell PJ (2001) Clinical role of positron emission tomography in oncology. Lancet Oncol 2: 157-164.

20. Pacak K, Eisenhofer G, Carrasquillo JA, Chen CC, Sheng-Ting Li, et al. (2001) 6-[18F] fluorodopamine positron emission tomographic (PET) scanning for diagnostic localization of pheochromocytoma. Hypertension 38: 6-8.

21. Dragulska S, Kanska M (2014) Enzymatic synthesis of tryptamine and its halogen derivatives selectively labeled with hydrogen isotopes. J Radioanal Nucl Chem 299: 759-763.

22. Banerjee N (2014) Neurotransmitters in alcoholism: A review of neurobiological and genetic studies. Indian J Hum Genet 20: 20-31.

23. Berger M, Gray JA, Roth BL (2009) The expanded biology of serotonin. Annu Rev Med 60: 355-366.

24. Gingrich JA, Hen R (2001) Dissecting the role of the serotonin system in neuropsychiatric disorders using knockout mice. Psychopharmacology 155: 1-10.

25. Giannaccini G, Betti L, Palego L, Marsili A, Santini F, et al. (2013) The expression of platelet serotonin transporter (SERT) in human obesity. BMC Neurosci 14: 128.

26. Palego L, Betti L, Rossi A, Giannaccini G (2016) Tryptophan biochemistry: Structural, nutritional, metabolic and medical aspects in humans. Journal of Amino Acids 2016: 1-13.

27. Lindemann L, Hoener MC (2005) A renaissance in trace amines inspired by a novel GPCR family. Trends Pharmacol Sci 26: 274-281.

28. Cambridge D, Whiting MV, Butterfield LJ (1992) The effects of combined angiotensin converting enzyme inhibition and beta-adrenoceptor blockade on plasma renin activity in anaesthetized dogs. Br J Pharmacol 106: 342-347.

29. Anwar MA, Ford WR, Broadley KJ, Herbert AA (2012) Vasoconstrictor and vasodilator responses to tryptamine of rat-isolated perfused mesentery: comparison with tyramine and b-phenyl ethylamine. $\mathrm{Br} \mathrm{J}$ Pharmacol 165: 2191-2202.

30. Stollak JS, Furchgott RF (1983) Use of selective anatagonists for determining the types of receptors mediating the actions of 5hydroxytryptamine and tryptamine in the isolated rabbit aorta. J Pharmacol Exp Ther 224: 215-221.

31. Saxena PR, Villalon CM (1990) Cardiovascular effects of serotonin agonists and antagonists. J Cardiovasc Pharmacol 15: 17-34.

32. Broadley KJ (2010) The vascular effects of trace amines and amphetamines. Pharmacol Ther 125: 363-375.

33. Conolan S, Quinn MJ, Taylor DA (1986) In vivo and in vitro activity of selective 5-hydroxytryptamine2 receptor antagonists. Br J Pharmacol 89: 129-135.

34. Connor HE, Feniuk W, Humphery PP, Perren MJ (1986) 5Carboxamidotryptamine is a selective agonist at 5-hydroxytryptamine receptors mediating vasodilatation and tachycardia in anaesthetised cats. Br J Pharmacol 87: 417-426.

35. Hamel E, Bouchard D (1991) Contractile 5-HT, receptors in human isolated pial arterioles: correlation with 5-HTID binding sites. Br J Pharmacol 102: 227-233.

36. Terron JA, Falcon-Neri (1999) Pharmacological evidence for the 5-HT7 receptor mediating smooth muscle relaxation in canine cerebral arteries. Br J Pharmacol 127: 609-616.
37. Ishine T, Bouchelet I, Hamel E, Lee TJ (2000) Serotonin 5-HT7 receptors mediate relaxation of porcine pial veins. Am J Physiol Heart Circ Physiol 278: H907-H912.

38. Leung E, Walsh LKM, Pulido-Rios MT, Eglen RM (1996) Characterization of putative 5-HT7 receptors mediating direct relaxation in Cynomolgus monkey isolated jugular vein. Br J Pharmacol 117: 926-930.

39. Trevethick MA, Fenuik W, Humphrey PP (1986) 5Carboxamidotryptamine: A potent agonist mediating relaxation and elevation of cyclic AMP in the isolated neonatal porcine vena cava. Life Sci 38: 1521-1528.

40. Hoyer D, Hannon JP, Martin GR (2002) Molecular, pharmacological and functional diversity of 5-HT receptors. Pharmacol Biochem Behav 7: 533-554.

41. Broadley KJ, Anwar MA, Herbert AA, Fehler M, Jones EM, et al. (2009) Effects of dietary amines on the gut and its vasculature. Br J Nutr 101: 1645-1652.

42. Kumar SS, Fazal Mohamed (2011) Synthesis, characterization and antibacterial activity of some novel tryptamines bearing pyrrolidin-2-one moiety. IJPLS 2: 1280-1286.

43. Adla SK, Sasse F, Kelter G, Fiebig HH, Lindel T (2013) Doubly prenylated tryptamines: cytotoxicity, antimicrobial activity and cyclisation to the marine natural product flustramine A. Org Biomol Chem 11: 6119-6130.

44. LJ, Chen G, Webster JM Webster (1997) Synthesis and antistaphylococcal activity of nematophin and its analogs. Bioorganic Med Chem Lett 7: 1349-1352.

45. Antolini M, Bozzoli A, Ghiron C, Kennedy G, Rossi T, et al. (1999) Analogues of 4, 5-bis (3, 5-Dichlorophenyl)-2-trifluoromethyl-1Himidazole as potential antibacterial agents. Bioorg Med Chem Lett 9: 1023-1028.

46. Collin AR (1999) Oxidative DNA damage, antioxidants and cancer. Bioessays 21: 238-246.

47. Kuruva CS, Katla VR, Kadiam CVS, Valluru L, Wudayagiri R, et al. (2013) Synthesis and antioxidant activity of novel phosphorylated tryptamine derivatives: QSAR DESCRIPTORS. Indo American Journal of Pharm Research 3: 1416-1426.

48. Sanders B, Lankenau SE, Bloom JJ, Hathazi D (2008) "Research Chemicals": Tryptamine and Phenethylamine Use among High-Risk Youth. Subst Use Misuse 43: 930-937.

49. Nichols DE (2004) Hallucinogens. Pharmacol Ther 101: 131-181.

50. Boland DM, Andollo W, Hine GW, Hearn WL (2005) Fatality due to acute alphamethyltryptamine intoxication. J Anal Toxicol 29: 394-398.

51. Rogawski MA, Aghajanian GK (1981) Serotonin autoreceptors in dorsal raphe neurons: Structure-activity relationships of tryptamine analogs. J Neurosci 1: 1148-1154.

52. Peden NR, Macaulay KEC, Bisset AF, Crooks J, Pelosi AJ (1981) Clinical toxicology of 'magic mushrooms' ingestion. Postgrad Med J 57: 543-545.

53. Tanaka E, Kamata T, Katagi M, Tsuchihashi H, Honda K (2006) A fatal poisoning with 5-methoxy-N, N-diisopropyltryptamine, Foxy. Forensic Sci Int 163: 152-154. 